\title{
BENTUK DAN PERAN MUSIK RANDAI PAREWA LIMO SUKU DALAM ACARA BARALEK DI KECAMATAN KURANJI KOTA PADANG SUMATERA BARAT
}

\author{
Rahmat Kurniawan
}

Pascasarjana Institut Seni Indonesia Yogyakarta e-mail : Kurniawanrahmat0808@gmail.com

Diterima : 12 April 2020. Disetujui : 15 Mei 2020. Dipublikasikan : 10 Juni 2020 (O2020 - DESKOVI Universitas Maarif Hasyim Latif. Ini adalah artikel dengan akses terbuka di bawah lisensi CC BY 4.0 (https://creativecommons.org/licenses/by/4.0/)

\begin{abstract}
ABSTRAK
Suku Minangkabau memiliki berbagai kesenian, di antaranya adalah Randai. Randai hidup dan berkembang dalam kehidupan masyarakat, dan hampir di setiap daerah di Minangkabau mempunyai Randai. Salah satu grup yang mengembangkan Randai yaitu Grup Parewa Limo Suku yang berada di Kuranji Kota Padang Sumatera Barat. Randai ini dilaksanakan dengan berbagai unsur seni yaitu Silek, Tari, Musik dan Teater. Randai termasuk kedalam Drama Musikal kedaerahan dengan memliki unsur seni yang kompleks. penyajian Randai diawali oleh permainan musik untuk menarik perhatian masyarakat. Berikutnya pidato dari Tukang Gore yang kemudian masuk ke dalam Legaran dengan diiringi musik untuk memberikan kesempatan kepada pelaku cerita memasuki lingkaran. Naskah cerita yang digunakan berjudul Untuang Sudah yang memiliiki permasalahan dan perselisihan dengan Rajo Angek Garang. Cerita ini dilaksanakan dalam lima legaran, cerita dalam Randai pada umumnya merupakan perumpamaan dalam masyarakat yang didalamnya mengandung nasehat-nasehat yang berisikan pesan moral. Cerita Untuang Sudah dalam Randai sering dibawakan dalam acara hiburan Baralek oleh Parewa Limo Suku. Musik iringan dalam Randai berperan sangat penting dimana musik membuat karakter suasana yang berbedabeda yakni sebagai ilustrasi cerita dan sebagai penguat suasana dalam penyampaian pesan di setiap adegan Randai. Tujuan Grup Parewa Limo Suku, yaitu untuk melestarikan kebudayaan Minangkabau, serta turut aktif membantu pemerintah dalam membina dan mengembangkan seni budaya khususnya seni budaya Minangkabau. Randai saat ini masih digunakan dalam pertunjukan rakyat Minangkabau dan bentuk penyajiannya disesuaikan dengan drama musikal yang menggunakan berbagai unsur-unsur kesenian yang ada dalam masyarakat Minangkabau. Penelitian ini menggunakan metode analisis deskriptif dan pendekatan Etnomusikologi.
\end{abstract}

Kata kunci: Baralek, Drama Musikal, Musik Iringan, Randai.

\section{ABSTRACT}

Minangkabau tribe has a variety of arts, including Randai. Randai lives and develops in community life, and almost every area in Minangkabau has Randai. One of the groups that developed Randai is the Parewa Limo Tribe Group located in Kuranji, Padang, West Sumatra. This randai is carried out with various elements of art namely Silek, Dance, Music and Theater. Randai included in the Regional Musical Drama with a complex element of art. Randai's presentation was preceded by a musical game to attract the attention of the public. Next was the speech from Tukang Gore which then entered Legaran accompanied by music to give the story actors a chance to enter the circle. The text of the story used is titled Untuang Sudah which has problems and disputes with Rajo Angek Garang. This story is carried out in five stories, the story in Randai is generally a parable in a society which contains advice which contains a moral message. Untuang Stories Already in Randai is often sung in Baralek entertainment programs by the Parewa Limo Tribe. Accompanied music in Randai plays a very important role where the music makes the character of a different atmosphere that is as an illustration of the story and as a reinforcement of the atmosphere in delivering messages in each Randai scene. The aim of the Parewa Limo Suku Group is to preserve the Minangkabau culture, and to actively assist the government in fostering and developing cultural arts, especially Minangkabau cultural arts. Randai is currently still used in Minangkabau folk performances and the form of presentation is adapted to musical dramas that use various artistic elements in the Minangkabau community. This research uses descriptive analysis method and ethnomusicology approach

Keyword : Baralek, Musical Drama, Musical accompaniment, Randai. 


\section{PENDAHULUAN}

Kebudayaan luar yang masuk ke Indonesia sangat berpengaruh dan mengancam keberadaan kebudayaan saat ini. Hal tersebut ditandai dengan menurunnya rasa kesadaran untuk melestarikan kebudayaan yang telah diturunkan secara turun temurun, salah satunya yaitu kesenian tradisional. Generasi penerus seolah-olah enggan untuk terlibat dalam upaya pelestarian budaya bangsa. Hal ini disebabkan perkembangan yang terjadi di berbagai ilmu pengetahuan, teknologi dan seni. Perkembangan ini tentu berdampak pada budaya yang ada, baik positif maupun negatif. Apabila hal ini terus berlanjut, dikhawatirkan akan terjadi krisis di Nusantara.

Kesenian tradisi merupakan warisan para pendahulu, sampai sekarang masih banyak ditemukan di berbagai daerah. Dari sekian banyak jumlah kesenian tradisi, ada yang masih utuh di pentaskan tetapi ada pula yang hampir punah sulit ditemukan, bahkan ada pula yang tidak sempat didokumentasikan dan disaksikan sampai sekarang. Begitu pula daerah Minangkabau yang memiliki berbagai macam jenis kesenian, tiap-tiap jenis mempunyai fungsi, bentuk dan tema yang berbeda. Di antara sekian jenis kesenian yang ada, Randai merupakan jenis kesenian yang menggunakan medium seni multi ganda, karena didukung oleh beberapa unsur seni, di antaranya seni musik, seni tari, seni teater, dan pencak. Oleh sebab itu sebagai penerus bangsa, wajib hukumnya bagi setiap insan menjaga serta melestarikan kebudayaan yang dimiliki. Berbagai kelompok masyarakat menerapkan pelestarian tersebut agar kebudayaan bisa terus hidup dan berkembang di masyarakat, salah satunya yaitu masyarakat di Kecamatan Kuranji Kota Padang.

Kecamatan Kuranji adalah salah satu dari kecamatan yang ada di Kota Padang Provinsi Sumatera Barat dengan kota kecamatan terletak di Pasar Ambacang. Kecamatan Kuranji berada dalam jarak 5 $\mathrm{km}$ dari pusat kota. Dengan beberapa kecamatan lainnya seperti Koto Tangah, Padang Utara, Padang Selatan, Padang Barat, Padang Timur, Lubuk Begalung, Lubuk Kilangan, Bungus, Teluk Kabung, Nanggalo dan Pauah. Mayoritas masyarakat Kuranji bersuku Minangkabau, selain masyarakat yang lahir di Kecamatan Kuranji, banyak juga para pendatang yang tinggal di Kuranji dengan alasan tertentu baik karena pendidikan atau tujuan pekerjaan. Dalam masyarakat Kuranji terdapat salah satu grup kesenian yang bertujuan untuk melestarikan seni pertunjukan tradisi, karena dengan seiring pekembangan jaman membuat kesenian tradisi mulai dilupakan dan mulai digantikan dengan kesenian dari luar negeri. Salah satu grup yang masih melestarikan kesenian tradisi tersebut adalah Parewa Limo Suku.

Parewa Limo Suku adalah grup musik yang pada awalnya sering membawakan beberapa jenis seni pertunjukan atau musik tradisi Minangkabau, seperti basaluang, barabab pasisie dan Randai untuk acara Baralek di Kecamatan Kuranji kota Padang. Pada perkembangannya, masyarakat setempat meminta grup Parewa Limo Suku untuk lebih sering menyajikan satu jenis pertunjukan yang di dalamnya terdapat unsur tarian, teater dan musik yang jenis pertunjukan tersebut dinamakan Randai. Randai selalu ditampilkan dalam acara hiburan Baralek. Baralek adalah istilah yang digunakan untuk perkawinan di Sumatera Barat (Minangkabau). Tradisi baralek di kecamatan kuranji selalu menampilkan acara basaluang, barabab dan Randai. Grup Parewa Limo Suku dalam acara baralek, selalu menampilkan Randai dengan musik iringan yang perpaduan antara permainan Gandang, saluang, bansi, dendang dan talempong. Pertunjukan Randai dilakukan di halaman rumah yang punya hajat atau alek, dan waktu pelaksanaannya di mulai pukul 20.00 sampai selesai atau biasanya sekitar 3 jam. Grup ini berdiri pada bulan maret 1987 yang awalnya beranggotakan 5 orang, yakni Suparman, Devi Hasri, Hendri Yusuf, Irmun Krismun dan Djamaluddin Umar. Pada perkembangannya, untuk melengkapi pertunjukan musik tradisi dan randai, terkadang grup Parewa Limo Suku menggunakan jasa dari pemain grup lainnya. Berdasarkan latar belakang di atas ada beberapa rumusan masalah yaitu, bagaimana peran dan fungsi musik dalam kesenian Randai di masyarakat Kecamatan Kuranji Kota Padang dan bagaimanakah bentuk penyajian musik dalam kesenian Randai grup Parewa Limo suku dalam acara Baralek.

\section{METODE PENELITIAN}

Metode penelitian berhubungan erat dengan prosedur, teknik, alat serta desain penelitian yang digunakan. Untuk itu memerlukan metodologi yang benar dan yang bisa dipertanggungjawabkan secara ilmiah. Pada bab ini akan diuraikan mengenai masalahmasalah tentang metodologi penelitian yang terdiri dari, subjek penelitian, alat yang digunakan, lokasi penelitian, metode pengumpulan data, jalannya penelitian, dan metode analisis data. Untuk itu sejalan dengan tujuan dan rumusan masalah penelitian, maka metode yang digunakan dalam penelitian ini adalah Metode penelitian kualitatif dengan pendekatan studi kasus (Case Study).

Pada dasarnya studi kasus mempelajari secara intensif dan rinci sesorang individu atau kelompok yang mengalami kasus tertentu. Data studi kasus dapat diperoleh dengan semua pihak yang bersangkutan, dengan kata lain dalam studi ini dikumpukan dari berbagai sumber. Subjek dapat berupa individu, kelompok, institusi atau masyarakat. Dalam kasus ini, peneliti mempelajari secara khusus dan mendalam dalam kurun waktu sekitar dua bulan lebih. Mendalam artinya, dengan mengungkap semua variabel yang dapat menyebabkan terjadinya kasus tersebut dari berbagai aspek. Peneliti terjun langsung mempelajari suatu proses atau penemuan yang terjadi secara alami, mencatat, menganalisis, menafsirkan, melaporkan, serta menarik kesimpulan dari proses tersebut. 
Subjek penelitiannya adalah empat orang narasumber dari pemain musik grup Randai Parewa Limo Suku. Pertama adalah salah seorang dari pendiri grup Parewa Limo Suku, pelatih di bagian musik , pelatih di bagian Tapuak Galembong. Dan salah seorang pemain musik sebagai perwakilan. Penentuan subjek atau narasumber penelitian mempertimbangkan pengalaman dalam hal bidang musik Randai yang di mainkan dalam grup.

Pengumpulan data dilakukan dengan wawancara dengan pendiri, pelatih di bagian musik, di bagian Randai, dan salah seorang pemain musik sebagai perwakilan. Wawancara ini dilakukan untuk mengumpulkan data guna menjawab permasalahan yang ada. Wawancara dan diskusi menggunakan tape recorder dengan mengajukan berbagai pertanyaan yang sudah dipersiapkan terlebih dahulu oleh peneliti. Selanjutnya catatan lapangan dan dokumen-dokumen juga menjadi salah satu alat pengumpulan data dalam penelitian ini.

\section{HASIL DAN PEMBAHASAN}

Grup Parewa Limo Suku berasal di Kecamatan Kuranji Kota Padang. Grup ini merupakan grup yang berkecimpung dalam kesenian Randai. Keberadaannya dalam kesenian tidak lepas dari kekompakan yang melekat erat dalam tubuh grup Parewa Limo Suku itu sendiri. Sejarah berdirinya grup Parewa Limo Suku juga ikut di prakarsai oleh masyarakat Kuranji, yang ingin mempertahankan kesenian tradisi Minangkabau agar tidak hilang karena perkembangan zaman. Pendiri Grup Parewa Limo Suku pada masa awal berdirinya mengumpulkan beberapa orang anaknya untuk dilatih barandai (ikut dalam randai). Setelah melewati masa tiga bulan anakanak yang belajar bertambah banyak. Perekrutan anggota Randai pada masa-masa awal berdirinya dilakukan lebih bersifat kekeluargaan dengan cara di sampaikan dari mulut ke mulut saja. Meskipun demikian setiap anak yang ikut bergabung latihan dengan Parewa Limo Suku disyaratkan harus sepengetahuan orang tua atau wali anak. Keberadaan Randai grup Parewa Limo Suku bermanfaat bagi masyarakat pecinta Randai. Hal ini dapat di buktikan dengan banyaknya tawaran untuk pertunjukan yang diajukan kepada grup Randai Parewa Limo Suku untuk menampilkan kreatifitas seni pertunjukannya. Tawaran-tawaran itu ada yang bersifat rutin dan berkelanjutan dan yang ditampilkan adalah kesenian Randai.

Randai adalah suatu jenis kesenian rakyat Minangkabau dengan menggunakan suatu cerita yang dilakukan di arena terbuka, berbentuk lingkaran dan merupakan medium cerita kaba, Kaba dalah cerita rakyat yang dibuat menjadi naskah cerita Randai. Setiap penggantian bagian pada Randai diselingi oleh gerakan tari, dendang dan cerita yang disuguhkan berasal dari sastra lama yang biasanya dapat berupa kritik, pujian, nasehat-nasehat atau unsur pendidikan untuk masyarakat pada saat itu. Randai menggunakan ibarat, kias, pantun serta pepatah dan petitih penuturan dialog dalam pertunjukan Randai oleh pemainpemainnya mengambil pengandaian atau perumpamaan kepada cerminan dalam masyarakat.

Proses dari pelatihan Randai pada awalnya bagi yang baru bergabung, para pelatih memberikan gerakangerakan dasar silek/silat terlebih dahulu agar anggota yang diajarkan tidak kaku. Setelah itu baru diajarkan gerakan berangkai dan gerakan baku. Apabila gerakan awal ini telah hafal maka gerakan tersebut disesuaikan dengan iringan musik, dengan dendang sekaligus menghafal naskah untuk cerita yang akan dibawa dalam pertunjukan Randai. Bagi yang ingin bergabung menjadi anggota biasanya mereka diantar oleh orang tua. Bagi para pemain setelah mereka bergabung dan belajar tentang gerakan yang diajarkan mereka sudah mulai terbiasa. Bagian gerakan pencak dan silek yang diiringi oleh alat musik Talempong Pacik dan Gandang.

Silek berasal dari kata si-liek yang artinya fisik, tubuh yang tangguh, liat (lincah) sehingga sulit ditangkap lawan dan juga dapat menghindari tangkapan atau sergapan lawan dan Galombang adalah sebutan untuk gerakan yang digunakan ketika adanya pergantian tiap bagian naskah, Secara umum seni bela diri tradisional Minangkabau disebut juga dengan pencak silat. Pencak silat secara umum yakni kegiatan yang mengandung unsur gerakan badan yang biasa dilakukan oleh pendekar-pendekar (pesilat) dalam membela diri atau menyerang lawan. Ketika melingkar mereka menggunakan gerakan pencak. Gerakan pencak dilakukan bervariasi sebagai pengembangan dari gerakan dasar pencak. Gerakan antara pemain ada yang beragam dan ada yang berlawanan, gerakan-gerakan itu mereka mainkan dengan sangat mahir. Tarian pencak adalah gerakan yang meyerupai pencak, baik dalam gerakan maupun dalam prinsipnya. Perbedaannya dengan pencak yaitu secara fisik pemain yang berhadapan tidak boleh bersinggungan dan sebagai tarian permainan itu diiringi bunyi-bunyian. Jadi gerakan tari dalam randai bersumber dari gerakan pencak dan gerakan silek. Gerakan pencak dilakukan saat pemain melingkar dan gerakan silek dilakukan pada saat perkelahian antara seorang tokoh dengan tokoh lain.

Salah satu masa peralihan sangat penting dalam hidup yaitu menginjak masa perkawinan/Baralek. Baralek adalah istilah yang digunakan untuk penyelenggaraan perkawinan di Sumatera Barat (Minangkabau). Dalam adat Baralek tradisi masyarakat Minangkabau, ada beberapa tatakrama dan upacara adat serta ketentuan agama islam yang harus dipenuhi. Tata krama tersebut seperti tatakrama jopuikmanjopuik (jemput menjemput), pinang meminang, batuka tando (bertukar cincin), akad nikah, jalang manjalang (datang-mendatangi), dan sebagainya. Tatakrama dan upacara adat perkawinan tersebut harus 
dipatuhi sebagai hal yang sakral. Karena masyarakat Minang menganggap bahwa "Perkawinan adalah sesuatu yang agung", yang harus diyakini hanya terjadi "sekali" seumur hidup. Tradisi baralek di kecamatan kuranji selalu menampilkan acara basaluang, barabab dan randai. Tradisi inilah yang membuat grup Parewa Limo Suku sering diundang oleh masyarakat, dengan di pentaskan Randai pada malam hari sebagai hiburan setelah prosesi pernikahan selesai.

Penyajian Randai mempunyai dua unsur pendukung yang saling berkaitan yaitu, unsur cerita dan musik. Setiap Randai menggunakan naskah cerita tradisional di Minangkabau, biasanya diambil dari cerita nyata atau legenda dalam lingkungan hidup masyarakat. Naskah cerita yang dipakai dalam penyajian Randai, kebanyakan mengangkat cerita rakyat yang populer seperti cerita Malin Kundang, Lareh Si Mawang, Cindua Mato, dan sebagainya, yang pada umumnya tidak diketahui penciptanya. Dari sekian jumlah cerita dalam Randai, ada satu cerita yang diciptakan oleh anggota grup Parewa Limo Suku, yang bernama Djamalludin Umar dengan judul. Cerita Untuang Sudah yang kemudian dipilih sebagai bahan kajian analisis yang dilaksanakan pada acara baralek di Kecaman Kurannji.

Untuang Sudah adalah nama orang dalam cerita ini, yang dalam cerita tersebut Untuang Sudah merupakan anak dari Tengku Rajo Tuo. Ayah dari Untuang Sudah yang dalam hal ini Tengku Rajo Tuo, meninggal dunia dan ketika itu masih punya urusan utang piutang dengan Rajo Gaek Garang. Urusan utang yang belum selesai tersebut berawal sejak Untuang Sudah belum lahir, dan Rajo Gaek Garang masih mempermasalahkan hutang piutang Tengku Rajo Tuo itu sampai Untuang Sudah, sudah dewasa. Setelah lima belas hari dari meninggalnya Rajo Tengku Tuo, lahirlah anaknya Rajo Tengku Tuo, yang kemudian dberi nama Untuang Sudah. Bayi tersebut kemudian dibawa ke kuburan ayahnya oleh ibunya, untuk bertemu dengan Biruang Sati yang kemudian diserahkan kepada Biruang Sati, yang kemudian dirawatnya hingga dewasa, sampai Untuang Sudah diajari cara mencari ikan ke laut. Setelah besar Untuang Sudah dijemput dan diambil kembali dari Biruang Sati oleh ibunya, yang kemudain dibawa pulang kembali. Hal ini dilakukan untuk menyelesaikan masalah utang ayahnya yang masih belum selesai kepada Rajo Gaek Garang. Sesampai di kampung halamannya, tampak Rajo Gaek Garang datang untuk kembali menuntut masalah ayahnya Untuang Sudah yang belum selesai. Utang ayah Untuang Sudah di bayar ketika sudah dewasa dan pertikaian antara Rajo Gaek Garang berakhir. Berakhirnya masalah Untuang Sudah tidak membuat Rajo Gaek Garang jera dengan terus mengusik kehidupannya, akhirnya Untuang Sudah kesal, lalu membunuh Rajo Gaek Garang didepan masyarakat banyak.

Bentuk pertunjukkan Randai terbagi beberapa bentuk pertunjukkan yaitu terdiri dari lima Legaran
(Bagian). Iringan musik Randai Parewa Limo Suku memiliki berbagai instrumen yang digunakan sesuai dengan fungsi dan jenisnya, baik itu dari segi organologi dan kesejarahannya. Instrumen yang digunakan adalah Talempong, Bansi dan Saluang.

Transkripsi bentuk musik tersebut menggunakan notasi angka dengan alasan bahwa, notasi ini cukup efektif sebagai bentuk transkripsi musik iringan Grup Parewa Limo Suku. Tangga Nada yang digunakan dalam iringan ini adalah diatonis. Berikut ini akan disajikan transkripsi dari bentuk musik iringan Parewa Limo Suku. Untuk memperjelas bentuk, penulisan notasi dibatasi dengan instrumen pokok yang mewakili melodi pokok dan ritmis. Bentuk salah satu transkripsi motif Talempong Pacik dan Dendang Dayang Daini adalah bentuk dari melodi pokok dalam musik iringan Randai.

Musik iringan Randai pada bagian pembuka dan penutup menggunakan motif Talempong Pacik, dengan menggunakan motif dasar, peningkah, anak dan gandang. Pada bagian ini masing-masing talempong menggunakan motif yang berbeda, dengan tempo yang tetap dan repetisi. Unsur lagu yang terdiri dari sejumlah nada yang dipersatukan dengan satu gagasan atau ide. Karena merupakan unsur lagu, maka sebuah motif biasanya diulang - ulang dan diolah.

Pertama menggunakan Motif Anak, motifnya hanya mengikuti tempo dan bersifat simetris. Orang yang memainkan motif dasar juga menjadi pemegang tempo, stabil atau tidaknya permainan talempong sangat ditentukan oleh motif anak ini.



Kedua Motif Dasar, fungsi motif ini sebagai melodi dasar dalam talempong pacik.

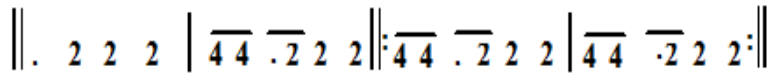

Ketiga Motif Peningkah, Fungsi motif Peningkah dalam talempong untuk menghasilkan motif yang rapat. Biasanya pemain peningkah akan menambah variasi sendiri ketika bermain.

$$
\left\|: \cdot \begin{array}{lllll}
1 & 2 & \overline{3} & 3
\end{array} \mid \cdot \begin{array}{llll}
1 & 2 & \overline{3} & 3
\end{array}\right\|
$$

Selanjutnya , Motif gandang berfungsi juga sebagai pengatur tempo, supaya tempo tetap stabil dan tidak kacau.

$$
\|: \mathbf{t} \cdot \overline{. t} \text { t } \mid t . \bar{t} t: \|
$$

Keterangan Simbol : 


$$
\mathbf{t}=\text { Dung }
$$

Berikut notasi full motif "Tigo Duo":

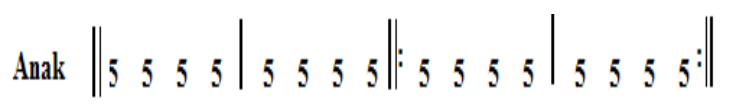

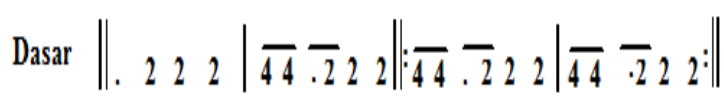



$$
\text { Gandang }\|t . \bar{t} t|t . \bar{t} t\|: t . \bar{t} t \mid t . \bar{t} t:\|
$$

Analisis syair pada Dendang Dayang Daini, penulisan notasi angka dalam tulisan ini menggunakan tangga nada diatonis. Dalam menganalisis lagu ini menggunakan istilah - istilah dasar dalam ilmu bentuk analisis musik yaitu motif, kalimat tanya, dan kalimat jawab

\section{$\overline{45} 566 \overline{65} 4 \ldots . .|\overline{45} 56 \overline{65} 4 \overline{3432} 1| 12 \overline{33} \overline{432} \overline{23} 3 \overline{32} 12 \overline{21} 3 \overline{32} 1 \mid$}

Potongan notasi di atas merupakan satu kalimat utuh dengan pola (A1-B1)-(A2-B2). Setiap satu kalimat lagu dengan pola (A1-B1)-(A2-B2) dilakukan pengulangan sebanyak satu kali. Pada nyanyian pertama hanya dinyanyikan oleh penyanyi Randai yang disebut tukang dendang sampai pola B2. Bagian pengulangan syair dinyanyikan oleh semua pemain yatu hanya pada bagian B2 termasuk para anak Randai juga ikut menyanyi, setelah tukang dendang menyanyikan 1 bait . Pengulangan dengan pola seperti itu dilakukan terus sampai syair habis dinyanyikan.

Potongan motif A1 sebagai motif pokok, yang merupakan motif tanya, dapat dilihat di bawah ini :

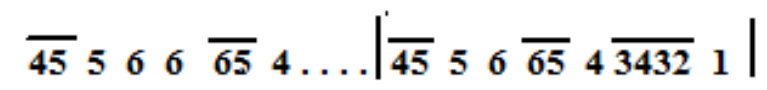

Kemudian dilanjutkan dengan motif A2 sebagai motif jawab dari motif A1:

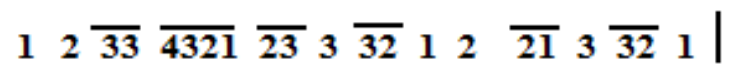

Motif B1 sebagai motif tanya :

$$
\overline{45}_{5} \overline{54}_{6} \overline{65}_{4}\left|\overline{45}_{5} \overline{43}_{6} \overline{65}_{4} \overline{3432}\right|
$$

Motif B2 sebagai motif jawab dari motif B1

$\begin{array}{lllllllllllll}1 & 2 & \overline{33} & \overline{4321} & \overline{23} & 3 & \overline{32} & 1 & 2 & \overline{32} & 3 & \overline{32} & 1\end{array}$

Potangan lagu Dayang Daini yang telah dijabarkan di atas, di dalamnya terdapat dua kalimat lagu yang masing - masing kalimat terdiri dari dua motif. Kalimat pertama adalah kalimat tanya A yang terdiri dari motif tanya A1 dan motif jawab A2. Kalimat kedua adalah kalimat jawab B yang terdiri dari motif tanya B1 dan motif tanya B2. Secara keseluruhan lagu dalam musik iringan Randai merupakan pengulangan dari kalimat tanya A dan kalimat jawab B yang dilakukan sebanyak satu kali pengulangan. Secara sederhana struktur Dendang Dayang Daini dapat dijelaskan sebagai berikut :

$\left.\begin{array}{l}\text { Mano sagalo niniak jo mamak } \\ \text { (Motif A1) } \\ \text { Cukuik panonton kasadonyo } \\ \text { (Motif A2) } \\ \text { Rila jo maaf kami pinta } \\ \text { (Motif B1) } \\ \text { Sagalo kami anak mudo } \\ \text { (Motif B2) }\end{array}\right\}$

Keterangan :

a. Satu bait lagu Dayang Daini terdiri dari 4 baris.

b. Setiap satu bait lagu terdapat dua kalimat, yaitu kalimat A sebagai kalimat pertanyaan dan kalimat B sebagai kalimat jawab.

c. Unsur terkecil dari kalimat lagu adalah motif. Dalam dendang Dayang Daini terdapat 4 motif, yaitu motif A1, motif A2, motif B1, dan Motif B2

d. Kalimat tanya A terdiri dari 2 motif, yaitu motif A1 sebagai motif tanya dan A2 sebagai motif jawab dari motif A1.

e. Kalimat jawab B terdiri dari 2 motif, yaitu motif B1 Sebagai motif tanya dan B2 sebagai motif jawab dari motif B1.

f. Tempo dendang diatur oleh pedendang sendiri, tidak menerapkan tempo.

Makna dari dendang tersebut adalah meminta maaf kepada semua ninik mamak atau pemangku adat yang ada, bahwa penampilan mereka belum sempurna dan seandainya terjadi kejanggalan dan kesalahan harap di maklumi. Dendang Dayang Daini merupakan suatu keharusan dan tidak pernah ditinggalkan oleh setiap grup randai. Selain untuk menyapa penonton, 
dendang ini juga berfungsi untuk berjaga-jaga agar penonton tidak mengganggu permainan Randai tersebut, baik gangguan sekedar iseng maupun gangguan yang serius. Dendang Dayang Daini juga mempunyai maksud agar nantinya cerita yang akan dibawakan tersebut dapat diterima dengan baik. Pemain Randai menginginkan kontak bathin antara mereka, sehingga cerita yang dibawakan akan lebih mudah dipahami.

Musik sebagai introduksi yang dimaksud dalam hal ini adalah sebuah musik pembuka yang mengawali sebuah babak atau sub babak dan musik pengantar ke sebuah suasana. Dalam introduksi ini sering dilakukan dengan menampilkan lagu yang sudah dikenal oleh penonton, sehingga walaupun tanpa syair (hanya instrumentalia), penonton sudah dapat menginterpretasikan makna lagu/ musik tersebut. Ilustrasi sebenarnya tidak jauh berbeda dengan introduksi, hanya saja musik sebagai ilustrasi digunakan untuk mendukung suasana tertentu. Musik ilustrasi biasanya menggunakan lagu-lagu yang sudah ada, akan tetapi tidak jarang juga menggunakan musik yang memang hanya membangun suasana tertentu. Setelah itu, musik iringan adalah musik yang digunakan untuk mengiringi lagu dan tarian. Lagu tentu saja sudah berarti musik, akan tetapi dalam hal ini adalah bahwa musik itu digunakan untuk mengiringi dialog yang yang dinyanyikan atau cerita tertentu yang dinyanyikan. Demikian pula hal nya dengan iringan tari, musik digunakan untuk tari-tarian yang ada dalam pertunjukan yang diangkat dari budaya kenyataan (bukan pertunjukan).

Fungsi musik Talempong pacik dalam Randai yaitu sebagai Paimbau, yang berfungsi untuk memanggil masyarakat bahwa akan ada pertunjukan Randai yang akan ditampilkan dalam acara hiburan baralek tanpa adanya gerakan Randai, hanya ditampilkan musik saja. Setelah itu, talempong pacik sebagai pengantar silek galombang, silek galombang adalah gerak dasar silat yang digunakan dalam gerakan randai. Musik iringan dalam Randai sangat mendukung suasana dalam cerita, biasanya dalam mengiringi ilustrasi cerita menggunakan saluang dan bansi.

Untuk menampilkan Randai dalam acara baralek Parewa Limo suku, format musik iringan selalu disesuaikan dengan perkembangan jaman. Menurut Hendri Yusuf "takluk kepada alam, takluk kepada pencipta, takluk kepada bunyi-bunyian" itu lah yang membuat masyarakat menjadi sangat peka dalam bunyi-bunyian yang didengar. Menurut filosofis orang Minangkabau, "alam takambang jadi guru, adaik basandi syarak, syarak basandi kitabullah, syarak mangato adaik manurun" masyarakat minangkabau selalu sensitif dengan bunyi-bunyian yang selalu didengarkan dalam kehidupan sehari, bunyi yang berasal dari alam seperti bunyi binatang atau tumbuhan yang hidup di alam.

Setiap alat musik yang digunakan dalam iringan Randai mempunyai fungsi masing-dalam legaran, legaran adalah bagian dalam cerita Randai. Talempong
Pacik berfungsi untuk pembuka dan penutup dalam Randai, menghimbau masyarakat sebagai tanda Randai akan dimulai. Untuk mengiringi Silek Galombang sebagai gerakan pembuka dalam randai. Saluang dan bansi berfungsi juga sebagai pembawa suasana dalam ilustrasi yang mana lebih banyak mengiringi suasana sedih, untuk memperkuat suasana cerita.

Dendang dalam Randai mempunyai aturan sendiri yang biasa dipakai, yaitu dendang Dayang Daini, Simarantang Randah, dan Simarantang Tinggi. Namun, karena dendang ini sudah biasa didengar oleh masyarakat, dendang ini menjadi dendang wajib ditampilkan dalam pertunjukan Randai, dengan apapun judul cerita yang akan ditampilkan. Dendang merupakan bagian penting dalam Randai, karena dendang adalah yang memperkuat suasana ketika naskah cerita yang tidak dapat divisualkan, dendang sebagai penyampai cerita dengan lirik atau syair. Lirik dendang berisikan pantun merupakan bagian dari sastra Minangkabau, sastra hidup dari satu generasi ke generasi berikutnya lewat alur-alur seni bertutur menurut corak dan gaya seni penuturnya. Corak sastra yang demikian itu mempunyai kedudukan dan keistimewaan sebagai karya sastra tradisi dalam pola budaya alam Minangkabau.

Alan P. Merriam (1964) mengklasifikasi fungsi musik terdapat menjadi sepuluh fungsi dan Randai adalah salah satu fungsinya yaitu fungsi sebagai hiburan. Randai berfungsi sebagai hiburan masyarakat dan untuk mempertebal rasa ketradisian juga memberi kesempurnaan terhadap adat istiadat Minangkabau sendiri, aspirasi dan media infrormasi rakyat. Randai adalah seni yang kolektif, yang di dalamnya terlibat sekumpulan orang yang bisa memupuk kebersamaan. Keberhasilan pertunjukan sangat tergantung pada kerjasama individu-individu yang ada di dalam kelompok. Selain itu, pertunjukan Randai memungkinkan adanya interaksi pemain Randai dengan penonton dan antar penonton serta terjalin kebersamaan. Fungsi tersebut antara lain sebagai seni hiburan, sebagai seni penyampaian pesan, nasehat dan pendidikan. Sebagai seni pertunjukan merupakan tontonan menarik bagi masyarakat sebagai media penyampaian pesan, peranannya sangat ampuh karena cara penyajiannya sangat menarik. Sumber ceritanya berasal dari kaba yang bertemakan budi, malu, susila, pendidikan dan penanaman kesadaran berbangsa. Jadi randai merupakan seni yang kompleks.

\section{KESIMPULAN}

Parewa Limo Suku tidak bisa terlepas dari masyarakat yang mendukungnya, karena ada hubungan antara pemain Randai dengan penonton dalam setiap pertunjukan. Dari segi musik iringan Randai Grup Parewa Limo Suku, musik yang digunakan seperti Talempong Pacik dan Dendang menjadikan ciri khas dari Randai, karena Randai tidak akan berjalan tanpa adanya musik ini. Randai menjadi kesenian yang 
kompleks karena memiliki unsur seni seperti teater, musik dan gerak tari. Faktor pendukung musik dalam Randai ada dua yaitu Internal dan Eksternal, faktor internal adalah bunyi yang dihasilkan yang tidak menggunakan medium alat musik seperti Dendang yaitu vokal dan tepukan atau gerakan yang dhasilkan oleh pemain yang menjadi suatu ritmis yang mempunyai unsur pola rhytem serta, musik faktor eksternal yang menggunakan media alat musik. Faktor eksternal yaitu menggunakan media alat musik seperti Talempong, Saluang, Bansi, dan Gandang. Keunikan inilah yang membuat Randai masih menjadi kesenian yang masih diminati oleh masyarakat. Tujuan awalnya grup ini yaitu untuk melestarikan kebudayaan Minangkabau dan menghindarkan generasi muda dari kegiatan yang negatif, turut aktif membantu pemerintah dalam membina dan mengembangkan seni budaya khususnya seni budaya Minangkabau.

\section{DAFTAR PUSTAKA}

Amir Adriyetti. dkk. (2006). Pemetaan Sastra Lisan Minangkabau. Padang : Universitas Andalas Press.

Banoe, Pono. (2003). Kamus Musik .Yogyakarta: Kanisius.

Esten, Mursal. (1994).Kajian Trasnformasi Budaya. Angkasa Bandung.

Merriam, Alan P. (1964). The Anthrophology of Music Chicago: North Western University Press.

M.S Amir. (1997). Adat Minangkabau Pola dan Tujuan Hidup Orang Minang. Jakarta : Mutiara Sumber Widya.

Navis, A.A. (1998). Alam Takambang Jadi Guru. Bukittinggi : Usaha Iklhas.

Prier, Karl-Edmund. (2004). Ilmu Bentuk Musik. Yogyakarta: Pusat Musik Liturgi

Sayuti Azinar, dkk. (1978). Perkembangan Seni Bela Diri Tradisional Minangkabau di Sumatera Barat.

Tumbidjo, H.B Datuk . (1979). Minangkabau dalam Seputar Seni Tradisional.

Zulkarnaini. (1995). Minangkabau Ranah Nan Den Cinto, Budaya Alam Minangkabau. Bukittinggi : Usaha Iklhas.

Zulkifli. (1993). Randai Sebagai Teater Rakyat. Jakarta: Kencana Indah. 
Rahmat Kurniawan / DESKOVI : Art and Design Journal, Vol. 3, No.1, Juni 2020, 65-72

(Halaman ini sengaja dikosongkan) 